\title{
3 Research Square \\ Decaying Logs Enrich Soil Fungal Communities in the Forest Ecosystem
}

\section{Qin Wang}

Taizhou University

Josep Peñuelas

Global Ecology Unit CREAF-CSIC-UAB, CSIC

\section{Bo Tan}

Sichuan Agricultural University

\section{Zhuang Wang}

Sichuan Agricultural University

Han Li

Sichuan Agricultural University

\section{Rui Cao}

Sichuan Agricultural University

\section{Chenhui Chang}

Sichuan Agricultural University

\section{Yurui Jiang}

Sichuan Agricultural University

\section{Wanqin Yang ( $\square$ scyangwq@163.com )}

Taizhou University https://orcid.org/0000-0003-1051-8607

\section{Research Article}

Keywords: decaying log, Abies faxoniana, soil fungal, community composition, functional group, subalpine forest

Posted Date: October 18th, 2021

DOl: https://doi.org/10.21203/rs.3.rs-977460/v1

License: (a) (i) This work is licensed under a Creative Commons Attribution 4.0 International License. Read Full License 


\section{Abstract}

Aims:

Soil fungi are crucial drivers of log decomposition in forest ecosystems. The objective of this study was thus to assess the conservation roles of decaying logs on soil fungi.

Methods:

Five classes of decaying Minjiang fir (Abies faxoniana) logs were incubated on the forest floor in a subalpine coniferous forest on the eastern Qinghai-Tibet Plateau, China, and the fungal communities compositions of the soil under decaying logs were assessed using high-throughput sequencing.

Results:

A total of 4321 operational taxonomic units (OTUs) were detected by Illumina MiSeq sequencing analysis. Basidiomycota and Ascomycota were dominant phyla regardless of log decay classes. With the log decomposition, the proportion of arbuscular mycorrhiza, wood saprotroph and saprotroph increased, but that of ectomycorrhiza decreased. Moreover, the diversity of soil fungal communities also increased along the decomposing process of logs. The decaying logs significantly altered soil fungal community composition by affecting biochemical properties (e.g. pH and concentrations of microbial biomass nitrogen and total phosphorus) and environmental factors (e.g. soil water content).

Conclusion:

Different decay classes of logs favor special fungal species, implying that the logs conservation with different decay classes in the forest ecosystem is of great significance for improving the diversity of soil fungi.

\section{Introduction}

Decaying logs are an important habitat for many organisms and play crucial roles in the global carbon cycle, soil formation, and water and soil conservation (Lassauce et al. 2011). The decomposition of logs is believed to be mainly carried out by fungi, whose hyphae can penetrate into the woody debris and secrete extracellular enzymes to decompose refractory organics such as lignocellulose (Baldrian and Banin 2017), finally release soluble substrates for microbial uptake (Moorhead et al. 2012). The logs are in direct contact with the soil surface and therefore might alter the structure of the fungal community of the underlying soil during the decomposition process. Zalamea et al. (2016) and Semchenko et al. (2018) have reported that the decomposition of logs directly affects the physical, chemical and biological properties of the soil under the logs. Minnich et al. (2021) have also found that deadwood can affect soil microbial community structure. Previous studies have reported the role of deadwood in the conservation of macrofungi, plants and invertebrates (Bani et al. 2018), but the responses of the composition and functional groups of soil fungal community to the decomposition of logs have rarely been studied. 
Soil fungi are key participants in the biogeochemical cycles of forest ecosystems, playing essential roles in the formation and development of soil, storage of soil carbon (C), nutrient cycling and energy flow (Tedersoo et al. 2014). The role of the soil fungal community is closely related to its structure and diversity, and the structure and diversity of the soil fungal community are affected by biological and abiotic factors such as hydrothermal environment, substrate quality and microbial eaters (Franklin and Mills 2009; Asemaninejad et al. 2018). Lindahl et al. (2007) have observed that the presence of woodrotting fungi in the soil, such as saprotrophic fungi, which are the main factor in decomposing organic matter and are critical in regulating nutrient cycling. Some fungal species are even found only in the soil under the decaying wood (Makipaa et al. 2017). In addition, some mycorrhizal fungi have the ability to colonize the wood substrate in contact with the soil surface, mineralize organic matter, and even tend to produce fruit bodies more often in wood than in soil (Lindahl and Tunlid 2015). Makipaa et al. (2017) have demonstrated that the structure of soil microbial communities under decaying logs at the initial stage of decomposition is relatively simple, but highly decayed wood released more ions into the surface layers of the soil than did less-decomposed wood (Jarosław et al. 2017). The stage of decomposition of deadwood affects the C:N:P stoichiometry of the soil (Wojciech et al. 2019), which may further cause the differences in soil fungal community structure. Thereby, the composition and diverstiy of soil fungal community might be closely correlated with log decay process, and affect the formation of soil organic matter.

Affected by the limitation of low temperature and frequent geological disasters, the soil in the subalpine forest on the eastern Qinghai-Tibet Plateau develops slowly and is often blocked (Yang and Wu 2021). Therefore, the organic layer of the soil and the decaying logs on the ground play an irreplaceable role in biodiversity conservation, material circulation, and water and soil conservation. The goal of this study was to analyze the effects of decaying logs on the composition of soil fungal communities and the response of the fungal community and functional groups to the heterogeneity of decay classes. We hypothesized that (1) decaying logs favor different groups of soil fungi thus enriching soil fungal communities; and (2) decaying logs would affect the fungal communities by altering soil biochemical properties and/or environmental factors. We tested these hypotheses by incubating decaying logs in a subalpine coniferous forest on the eastern Qinghai-Tibet Plateau, China. Minjiang fir (Abies faxoniana) is the dominant tree species in this region. Minjiang fir logs at various stages of decay were incubated for six years on the forest floor, and the compositions of the soil fungal communities in the soil under the logs were determined using high-throughput sequencing. The objective of this study was thus to assess the conservation roles of decaying logs on soil fungi.

\section{Materials And Methods \\ 2.1 Site description}

The study was conducted at the Long-Term Research Station of Alpine Forest Ecosystems $\left(31^{\circ} 14^{\prime}-31^{\circ} 19^{\prime} \mathrm{N}, 102^{\circ} 53^{\prime}-102^{\circ} 57^{\prime} \mathrm{E} ; 2458-4619 \mathrm{~m}\right.$ a.s.I.) in Li County, Sichuan Province, southwestern China. The region is a transitional area between the Tibetan Plateau and the Sichuan Basin. The annual 
mean temperature and precipitation are approximately $2-4^{\circ} \mathrm{C}$ and $850 \mathrm{~mm}$, respectively (Chang et al. 2019). The seasonal soil freeze-thaw period begins in early November and ends in April the following year. The soil is classified as Cambisols and Primosols (Xiao et al. 2014). The accumulation of large amounts of woody debris $\left(53 \mathrm{t}^{\mathrm{th}} \mathrm{h}^{-1}\right)$ in this region (Xiao et al. 2016) plays crucial roles in maintaining soil fertility, controlling soil erosion and promoting biodiversity. The trees consist mainly of Minjiang fir (Abies faxoniana), cypress (Sabina saltuaria), larch (Larix mastersiana) and red birch (Betula albosinensis), with Minjiang fir accounting for $80 \%$ of the total basal area at the site (Xiao et al. 2014). The main understory shrubs include willow (Salix paraplesia) and azalea (Rhododendron lapponicum).

\subsection{Experimental design}

We established a permanent $100 \times 100 \mathrm{~m}$ plot of primary Minjiang fir forest in the nature reserve in August 2013 based on previous studies (Chang et al. 2019; Chang et al. 2020) and three $25 \times 25 \mathrm{~m}$ subplots with similar slope aspects, slope degrees, canopy closures and tree heights. Logs $35 \pm 5 \mathrm{~cm}$ in diameter in five classes of decay (I-V, at increasing levels of decay) described in detail by Chang et al. (2019) and Wang et al. (2021) were collected. The logs of decay class I were from newly felled trees, representing the start of decomposition, and the logs of classes II-V were collected from the primary coniferous forest. All logs were sawed on-site into lengths of $120 \mathrm{~cm}$ and carefully placed into the closed canopy in each subplot. Six sections of the logs in the same decay class were incubated on the forest floor in each subplot. See Chang et al. (2020) and Wang et al. (2021) for more details. This experiment studied the three sections where epixylic vegetation was not removed.

\subsection{Sampling}

Soil samples were collected in August 2019 from the 0-10 cm layer in each subplot using an auger $(5 \mathrm{~cm}$ diameter) after the decaying logs were carefully removed. Control samples (CK) were also collected $>3 \mathrm{~m}$ from the decaying logs. The samples were transported to the laboratory on ice packs in a cooler. A total of 54 soil samples were collected [ $(1 \mathrm{CK}+5$ decay classes $) \times 3$ replicates $\times 3$ subplots]. Visible living plant material was removed from the samples, and about $20 \mathrm{~g}$ of soil was used to determine the water content (WC). The samples were passed through a 2-mm sieve, and subsamples were stored at -70 and $4^{\circ} \mathrm{C}$ for molecular and biochemical analysis, respectively. The remaining subsamples were air-dried and passed through $0.149-\mathrm{mm}$ sieves, placed in sealable bags and stored at room temperature for elemental analysis. Five of the nine replicate samples were randomly selected, for a total of 30 samples.

\subsection{Soil physiochemical and biological analyses}

Water content was determined by weighing the samples before and after drying. Soil pH was measured using a pH meter at a soil: water ratio of $1: 2.5(\mathrm{~m} / \mathrm{v})$. The concentrations of organic $\mathrm{C}(\mathrm{OC})$, total nitrogen (TN) and total phosphorus (TP) in soil were measured using potassium dichromate oxidation-ferrous sulfate titrimetry, Kjeldahl determination and molybdenum-antimony colorimetry, respectively (Lu 1999). Soil microbial biomass $\mathrm{C}(\mathrm{MBC})$ and microbial biomass nitrogen (MBN) were measured using chloroform fumigation and $\mathrm{K}_{2} \mathrm{SO}_{4}$ extraction (Brookes et al. 1985; Vance et al. 1987). Soil microbial biomass 
phosphorus (MBP) was measured using chloroform fumigation and $\mathrm{NaHCO}_{3}$ extraction (Brookes et al. 1982).

\subsection{DNA extraction, PCR amplification and high-throughput sequencing}

Microbial DNA was extracted from the samples using the FastDNA Spin Kit for Soil (MP Biomedicals, Solon, USA) following the manufacturer's instructions. DNA was checked for quality using agarose gel electrophoresis and ultraviolet absorbance (ND1000, Nanodrop, Thermo Fisher Scientific, Waltham Mass, USA). The DNA was diluted to $1 \mathrm{ng} / \mu \mathrm{l}$ using sterile water and stored at $-20^{\circ} \mathrm{C}$ until analysis.

A region of the fungal ITS2 gene was amplified, purified, quantified, pooled and sequenced on an Illumina NovaSeq platform at Novogene Genomics Institute (Beijing, China). The fungal ITS2 gene was amplified using the primer pair ITS3-2024F (GCATCGATGAAGAACGCAGC)/ITS4-2409R

(TCCTCCGCTTATTGATATGC). PCR products were detected by electrophoresis in a $2 \%(\mathrm{w} / \mathrm{v})$ agarose gel, and bands were excised, mixed in equal density ratios and purified using a GeneJET Gel Extraction Kit (Thermo Fisher Scientific, Waltham Mass, USA). The purified PCR products were sequenced on the Illumina NovaSeq platform by Pair-End (When constructing the DNA library to be tested, binding sites of sequencing primer were added on the adapters at both ends). The raw data were then controlled for quality using UPARSE. USEARCH was used to identify and remove chimeras, and the remaining sequences were clustered to generate operational taxonomic units (OTUs) at the $97 \%$ similarity level (Edgar 2010; Magoč and Salzberg 2011). Quantitative Insights Into Microbial Ecology (QIIME) was used to process and analyze the high-quality sequences (Kuczynski et al. 2011). Representative sequences were deposited in the UNITE database for fungi.

In addition to taxonomic composition, the fungal functional groups were further anticipated based on FUNGuild (Nguyen et al. 2016). The fungi could be assigned to a guild with the confidence level of "probable" or "highly probable". We classified the fungal taxa into six functional groups (i.e., animal pathogen, arbuscular mycorrhiza, ectomycorrhiza, plant pathogen, wood saprotroph and saprotroph) with some overlaps. This functional prediction method is broadly used to realize soil fungal communities (Pfennigwerth et al. 2018; Semchenko et al. 2018).

\subsection{Statistical analyses}

We used one-way ANOVAs to test the effect of the extent of decay on the concentrations of MBC, MBN, MBP, OC, TN and TP. The diversity indices (Shannon and Simpson) and richness estimators (Chao1 and abundance-based coverage estimator (ACE)), metrics of alpha diversity of the soil fungal communities, were calculated. The effects of the decay classes on fungal community structure were further tested using nonmetric multidimensional scaling (NMDS) with OTUs. Heatmap was used to show compositions of fungal functional groups inferred by FUNGuild from different decay classes of logs. Spearman correlation analysis was used to identify relationships between soil physicochemical properties and the relative abundances of fungal taxa. The metrics of alpha diversity and the NMDS, heatmap and 
Spearman analyses were performed using the VEGAN package (Oksanen et al. 2013) in R ( $R$ Development Core Team 2015). Other statistical analyses were performed using SPSS 20.0 (IBM Corporation, Armonk, USA). The statistical tests were considered significant at $P<0.05$.

\section{Results}

\subsection{Soil microbial biomass and $\mathrm{C}, \mathrm{N}$, and $\mathrm{P}$ concentrations}

The soil concentrations of MBN, MBP, OC, TN and TP were significantly higher in the higher decay classes $(P<0.01)$, but the MBC concentration did not differ significantly among the classes $(P=0.052)$ (Fig. 1$)$.

The concentrations of microbial biomass, $\mathrm{OC}$ and TN were higher in the soil under the decaying logs than in CK. The much higher concentrations of MBN, MBP, OC and TN relative to CK began in classes III, II, II and I, respectively. The TP concentration was lower in the soil under the decaying logs in classes I-III than in CK but did not differ significantly between classes IV and V and CK.

\subsection{Characteristics of the sequence data and species alpha diversity}

Pyrosequencing of 30 soil samples under decaying logs produced total 3344637 raw fungal sequences, and 1926264 high-quality fungal sequences were retained after the raw sequences were controlled for quality. The sequence data were classified into 4321 fungal OTUs at a cutoff in sequence similarity of $97 \%$. The Shannon-Wiener and Simpson diversity indices for the fungal communities differed significantly among the decay classes $(P<0.05)$ and were the highest for DC3 and DC4. The number of OTUs and the Chao1 and ACE richness indices for the fungal community, however, did not differ significantly among the classes or between CK and the soil under the decaying logs $(P>0.05)$ (Table 1$)$. However, no difference in OTUs and richness (Chao1 and ACE indices) of soil fungal community was observed between log decay classes, neither between the soil samples of blank control group versus soil under decaying logs $(P>0.05)$. The number of unique fungal OTUs was higher under the decaying logs than CK (except for DC4) (Fig. S1). 
Table 1

Number of operational taxonomic units (OTUs) and indices of alpha diversity for the fungal communities in the soil under decaying logs for the decay classes (mean $\pm S D$, $n=5)$. CK, control; DC1-DC5, decay classes I-V. Different letters within a column indicate significant differences $(P<0.05)$ among the classes.

\begin{tabular}{|llllll|}
\hline Class & No. OTUs & Shannon & Simpson & Chao1 & ACE \\
\hline CK & $607 \pm 199 \mathrm{a}$ & $3.84 \pm 0.72 \mathrm{~b}$ & $0.734 \pm 0.055 \mathrm{c}$ & $1265 \pm 395 \mathrm{a}$ & $1051 \pm 319 \mathrm{a}$ \\
\hline DC1 & $684 \pm 48 \mathrm{a}$ & $4.63 \pm 0.40 \mathrm{~b}$ & $0.832 \pm 0.050 \mathrm{~b}$ & $1394 \pm 129 \mathrm{a}$ & $1132 \pm 97 \mathrm{a}$ \\
\hline DC2 & $663 \pm 166 \mathrm{a}$ & $3.76 \pm 0.48 \mathrm{~b}$ & $0.722 \pm 0.053 \mathrm{c}$ & $1476 \pm 467 \mathrm{a}$ & $1200 \pm 290 \mathrm{a}$ \\
\hline DC3 & $845 \pm 160 \mathrm{a}$ & $6.14 \pm 0.45 \mathrm{a}$ & $0.9551 \pm 0.016 \mathrm{a}$ & $1467 \pm 381 \mathrm{a}$ & $1245 \pm 275 \mathrm{a}$ \\
\hline DC4 & $790 \pm 178 \mathrm{a}$ & $6.07 \pm 0.92 \mathrm{a}$ & $0.954 \pm 0.029 \mathrm{a}$ & $1539 \pm 767 \mathrm{a}$ & $1198 \pm 342 \mathrm{a}$ \\
\hline DC5 & $890 \pm 115 \mathrm{a}$ & $5.94 \pm 1.09 \mathrm{a}$ & $0.929 \pm 0.059 \mathrm{a}$ & $1637 \pm 164 \mathrm{a}$ & $1355 \pm 119 \mathrm{a}$ \\
\hline
\end{tabular}

\subsection{Taxonomic composition of fungi}

Basidiomycota (22.0-49.3\%), Ascomycota (15.7-41.5\%) and Mortierellomycota (2.4-11.9\%) were the most dominant fungal phyla, representing $>65 \%$ of the total reads (Fig. 2a). The relative abundance of Mortierellomycota was significantly higher in the soil under the decaying logs than in CK and was the lowest in DC2 and the highest in DC4 $(P<0.05)$. The relative abundance of Basidiomycota decreased as the decay class increased, and Ascomycota had the opposite trend, but the relative abundances of Basidiomycota and Ascomycota did not differ significantly among the classes (Figs. 2a and S2a). The relative abundances of other phyla, including Rozellomycota, Glomeromycota, Chytridiomycota and Mucoromycota, were $<1 \%$. The relative abundances of all these phyla except Mucoromycota were significantly affected by the decaying logs.

A total of 24 fungal genera (relative abundance $>1 \%$ ) were identified across all samples (Fig. 2b). Piloderma, Inocybe and Mortierella were the three most abundant genera. The relative abundance of Piloderma was higher (except for DC5), the relative abundance of Inocybe was lower (except for DC3) and the relative abundance of Mortierella was higher in the soil under the decaying logs than in CK (Figs. 2b and S2b). The relative abundances of most of the other genera, such as llyonectria, Fusarium, Sebacina, Russula, Phlebia, Humicola and Pleotrichocladium, were significantly higher for the decay classes than CK (Fig. S2b).

NMDS of Bray-Curtis distances was used to compare the similarity of the soil fungi between CK and the decay classes (Fig. 3a). The taxonomic composition of the soil fungal communities differed significantly among the classes (stress $<0.2$ ). 


\subsection{Compositions of fungal functional group inferred by FUNGuild}

The relative abundance of most putative fungal functional groups was significantly affected across the treatments (Fig. 4). The proportion of arbuscular mycorrhiza, wood saprotroph and saprotroph increased with the increase of the decay classes of logs, while the proportion of ectomycorrhiza decreased. Additionally, the relative abundance of wood saprotroph did not differ between CK and decay classes I-III but increased drastically at decay class IV. The relative abundance of animal pathogen reached its maximum value at the decay classes IV, while the relative abundance of plant pathogen reached its maximum value at the decay classes III. Heatmap of soil fungal functional groups showed that the soil under the decay class I of logs and the soil at CK were gathered into the same branch, and the soil under decay class IV and $\mathrm{V}$ of logs were gathered into the same branch (Fig. 3b).

\subsection{Correlations between fungal taxonomic composition and soil biochemical properties}

Spearman correlation heatmaps were analyzed to identify the relationships of the fungal communities with biochemical properties and environmental factors (Fig. 5). Soil pH and the concentrations of MBC, MBN and TP and were important factors influencing the relative abundances of Basidiomycota and Ascomycota (the two phyla with the highest relative abundances) and were correlated positively with the relative abundance of Basidiomycota but negatively with the relative abundances of Ascomycota, Glomeromycota and Chytridiomycota (except for pH) (Fig. 5a). Water content and the concentrations of MBC, MBN and TP were negatively correlated with the relative abundances of the genera llyonectria, Fusarium, Humicola, Pleotrichocladium, Chaetomium, Tetracladium, Dactylonectria, and Didymosphaeria, but the concentrations of MBC, MBN, MBP and $\mathrm{OC}$ were positively correlated with the relative abundances of Cortinarius and Meliniomyces. $\mathrm{pH}$ was positively correlated with the relative abundances of llyonectria, Fusarium, Humicola, Pleotrichocladium, Chaetomium, Tetracladium and Dactylonectria (Fig. 5b).

\section{Discussion}

Decaying logs contribute greatly to the overall compositions of soil fungal communities. Logs increased the diversity of the fungal communities, thereby altering their compositions, consistent with our hypotheses. The diversity of the soil fungal community increased as the decay class increased. The decaying logs, however, did not affect the richness of the soil fungal community and the relative abundance of dominant species. The proportion of functional groups varied with decay classes of logs, indicating that decaying logs favor different functional groups of soil fungi, rather than dominant species thus enriching soil fungal communities. The composition of fungal communities of the soil under decaying logs was closely related to biochemical properties (e.g. $\mathrm{pH}$, concentrations of microbial biomass nitrogen and total phosphorus) and environmental factors (e.g. soil water content). Our results indicated the conservation of logs with different decay classes in the forest ecosystem is of great significance for improving the diversity of soil fungi. 


\subsection{Variation of biochemical properties in soil under decaying logs}

The soil concentrations of MBN, MBP, OC and TN were higher under the decaying logs than in CK. Previous studies have reported the same trend. Kappes et al. (2007) have found that the presence of coarse woody debris improved the chemical and biotic parameters of soil in acidified broadleaved forests. Adamczyk et al. (2016) have reported that the removal of coarse woody residue negatively affected the soil microbial biomass and net $\mathrm{N}$ mineralization, since the decomposition and use of decaying logs by soil microorganisms break organic matter down into inorganic substances and participates in soil processes through the debris food chain. The concentrations of MBN, MBP, OC, TN and TP in the soil under decaying logs also increased significantly with the decay class, indicating that the heterogeneity among the decay classes significantly affected the biochemical properties of the soil (Wojciech et al. 2019). MBC concentration, however, did not differ significantly among the classes, implying that the effect of decaying logs was probably more important for the acquisition by soil microbes of $\mathrm{N}$ than $\mathrm{C}$ (Adamczyk et al. 2016).

\subsection{The diversity of soil fungal communities increased along the log decomposition}

The Shannon-Wiener and Simpson indices for the soil fungal communities differed significantly among the decay classes and were the highest in the late stage of decay, suggesting that the fungal communities in the soil under the decaying logs increased in species richness during the decay of the logs. The results for fungi were consistent with those reported by Makipaa et al. (2017), who found that the fungal community in the wood was more similar to that in the soil in the late stage of decay than early stage of decomposition and that some microbial species occurred in the soil only when decaying logs were present on the soil surface. Decaying logs serve as an additional source of nutrients but also provide a more stable moisture content of the soil surface in the late stage of decay (Zalamea et al. 2016), offering beneficial habitat conditions for some mycorrhizal species. The Chao1 and ACE richness indices for the soil fungal community in our study did not differ significantly among the decay classes. The presence of the decaying logs, especially highly decayed logs, thus affected the composition of soil microbial communities.

\subsection{Effect of decaying logs on taxonomic composition of soil fungi}

Basidiomycota and Ascomycota were the two dominant phyla across CK and all decay classes, consistent with a previous study (Chen et al. 2017). Other studies have reported that exogenous materials such as plant litter and wood were the main sources of $\mathrm{C}$ for Basidiomycota, which can degrade lignin and humic acids (Purahong et al. 2016), but the relative abundance of Basidiomycota in our study did not differ significantly between the soil under the decaying logs and CK, indicating that the abundance of dominant fungal species is determined by the regional climate and soil type. The relative abundance of 
Basidiomycetes and Ascomycetes was generally lower in the soil under the decaying logs than in CK, perhaps owing to some wood-decaying fungi can colonize the soil, thereby increasing fungal diversity under decaying logs and decreasing the relative abundances of these two groups of fungi. The relative abundances of some Basidiomycota genera, such as Piloderma, Inocybe, Sebacina, Russula and Phlebia, and that of some Ascomycete genera, such as Ilyonectria, Fusarium, Humicola and Pleotrichocladium (Fig. S3), however, differed significantly among the decay classes, indicating that, in addition to mycorrhizal capacity, these soil fungi also have the capacity to decompose wood. Previous studies have demonstrated that some mycorrhizal groups have retained mechanisms of decomposition similar to those of brown- and white-rot fungi and actively participate in the decomposition of organic matter (Lindahl and Tunlid 2015). Mortierellomycota, a typical species found in soil (Lindahl et al. 2007), was as abundant in heavily decayed wood as in soil (Makipaa et al. 2017). Some phyla with lower relative abundances in our study were also significantly differentially represented in the decay classes. Decaying logs are thus an important source of nutrients for some soil fungal communities.

\subsection{Response of soil fungal functional group to log decomposition}

According to the classification results of FUNGuild, the relative abundance of fungal functional groups varied with the trophic mode in the decomposing process of logs. Pathogenic, saprotrophic, and symbiotic fungi can drive plant-soil feedbacks in complex ways (Semchenko et al. 2018). Pathogenic fungi obtained nutrients by damaging host cells. The results implied that pathogenic fungi colonized on decaying logs at the initial stage of decomposition, and began to damage plant cells in a large amount in the intermediate stage of decomposition. Wojciech et al. (2019) have demonstrated that the logs in the first and second stages of decay, without clear signs of decomposition. Besides, the soil under Minjiang fir decaying logs was dominated by saprotrophic fungi. Wood saprotroph and saprotroph were heterotrophic organisms that obtain a major fraction of their metabolic carbon from dead organic matter (Lindahl and Tundia 2015). Previous studies have shown that soft-rot fungi were common in the early stages but white- and brown-rot fungi became dominant as decay progressed (Rajala et al. 2011). In this study, the relative abundance of wood saprotroph and saprotroph increased drastically at decay class IV, indicating that more saprophytes were needed to decompose refractory organics such as lignocellulose at the highly decayed logs.

Arbuscular mycorrhizal fungi acquired carbon from host plants and obtained substantial amounts of nitrogen from decomposing organic materials (Hodge and Fitter 2010), and deliver mineral nutrients to the host, in particular phosphate (Ezawa and Saito 2018). Coline et al. (2018) have shown that water availability played a key role in affecting soil arbuscular mycorrhizal fungi. Therefore, with the increase of nutrients and moisture content, the relative abundance of Arbuscular mycorrhizal fungi increased with the decomposing process of logs. Our findings are contrary to previous studies that have demonstrated that ectomycorrhizal fungi became the most abundant group in the late stages of succession (Rajala et al. 2011). Lindahl and Tunlid (2015) have proposed that ectomycorrhizal fungi do not regularly use organic matter as a source of metabolic carbon, but rather that their access to host sugars facilitates co- 
metabolic degradation of complex, recalcitrant organic complexes, thereby releasing $\mathrm{N}$ from organic pools, which may explain why ectomycorrhizal fungi are less affected by the decay classes of logs. In addition to the changes in soil nutrients and environmental conditions, the interaction between fungi with different trophic modes also affected the proportion of fungal functional groups (Lindahl et al. 1999). The results indicated that logs with different decay classes conserved different soil fungi groups.

\subsection{Influencing factors of soil fungal community composition}

Organic matter is an important component of soil, and its concentration strongly affects the structure and function of soil microbial communities (Grayston et al. 2004; Franklin and Mills 2009). The composition of soil OC affects the abundance and structure of microbial communities (Zhang et al. 2020). N addition can also alter the composition of soil fungal communities, such as symbiotic mycorrhizal fungi (Morrison et al. 2016; Corrales et al. 2017). The concentrations of OC and TN in our study were poorly correlated with the relative abundances of the soil microorganisms, but the concentrations of MBC and MBN significantly affected the relative abundances of fungi, perhaps due to the role of highly heterotrophic metabolic microorganisms such as saprophytes. Changes to the concentrations of MBC and MBN could then better represent the dynamic changes of microorganisms in soil under decaying logs than could the concentrations of OC and TN. The concentration of TP is among the main factors influencing microbial activity at regional spatial scales (Cao et al. 2016). The concentration of TP in our study was significantly correlated with the relative abundances of some of the fungal communities. Similar observations were also reported for soil planted with Chinese kale (Pongsilp and Nimnoi 2020). The significant differences in MBC, OC and TP concentrations among the decay classes may to some extent account for the separation of Glomeromycota.

Soil pH is also a critical factor for the diversification of fungi and strongly influences the structure of soil microbial communities (Geisseler and Scow 2014). pH can directly affect soil microbial communities and indirectly affect the structure of some microbial communities through interactions among soil elements (e.g. precipitation of ions) (Lammel et al. 2018). The dominance of some phyla in our study, such as Basidiomycetes and Ascomycetes, depended strongly on soil pH. Water content was also strongly correlated with the characteristics of the microbial communities (Brockett et al. 2012). These results indicated that the dominant fungi in the soil under decaying logs might respond to the changes in water content by the allocation of limited resources.

\section{Conclusion}

This study examined the effects of decaying logs on the composition of soil fungal communities in a subalpine forest. Our results showed that decaying logs affected the compositions of soil fungi and enrich soil fungal communities. The abundances of the dominant species of soil fungi were not significantly affected by the decomposition of the logs, indicating that the soil fungi could maintain stable community structures by self-regulation. Additionally, decaying logs favor different functional 
groups of soil fungi, and fungal functional groups of soil under highly decayed logs tended to be similar. Biochemical properties (e.g. pH, the concentrations of MBN and TP) and environmental factors (e.g. water content) in our study accounted to some extent for the heterogeneity of the fungal communities among the decay classes. Therefore, the conservation of logs with different decay classes in the forest ecosystem is of great significance for improving the diversity of soil fungi. Log decomposition is a longterm and complex biological process, so the response of soil microorganisms to the decomposition of logs needs long-term experimental research.

\section{Declarations}

\section{Author contributions}

W.Q.Y. and B.T. conceived and designed the experiment and contributed resources. Q.W. completed laboratory analysis and led the writing of the manuscript. Q.W., B.T., Z.W., H.L., R.C., C.H.C., and Y.R.J. contributed to field work. W.Q.Y., and J.P. provided writing assistance. All authors have read and agreed to the published version of the manuscript.

Funding: This work was supported by the National Natural Science Foundation of China (grant numbers 32071745, 31870602 and 31901295), and the Program of Sichuan Excellent Youth Sci-Tech Foundation (grant numbers 2020JDJQ0052). We are also grateful for the financial support from the China Scholarship Council, China, and the Spanish government project PID2019-110521GB-I00.

\section{Declaration of competing interest}

All authors certify that they have no affiliations with or involvement in any organization or entity with any financial interest or non-financial interest in the subject matter or materials discussed in this manuscript.

\section{References}

1. Adamczyk S, Kitunen V, Lindroos AJ, Adamczyk B, Smolander A (2016) Soil carbon and nitrogen cycling processes and composition of terpenes five years after clear-cutting a norway spruce stand: effects of logging residues. Forest Ecology Management 381:318-326. http://doi.org/10.1016/j.foreco.2016.09.034

2. Asemaninejad A, Thorn RG, Branfireun BA (2018) Climate change favours specific fungal communities in boreal peatlands. Soil Biology Biochemistry 120:28-36. http://doi.org/10.1016/j.soilbio.2018.01.029

3. Baldrian P, Banin E (2017) Forest microbiome: diversity, complexity and dynamics. FEMS Microbiology Reviews 41:109-130. http://doi.org/10.1093/femsre/fuw040

4. Bani A, Pioli S, Ventura M, Panzacchi P, Borruso L, Tognetti R, Tonon G, Brusetti L (2018) The role of microbial community in the decomposition of leaf litter and deadwood. Applied Soil Ecology 126:75-84. http://doi.org/10.1016/j.apsoil.2018.02.017 
5. Brockett BFT, Prescott CE, Grayston SJ (2012) Soil moisture is the major factor influencing microbial community structure and enzyme activities across seven biogeoclimatic zones in western Canada. Soil Biology Biochemistry 44:9-20. http://doi.org/10.1016/j.soilbio.2011.09.003

6. Brookes PC, Powlson DS, Jenkinson DS (1982) Measurement of microbial biomass phosphorus in soil. Soil Biology Biochemistry 14:319-329. http://doi.org/10.1016/0038-0717(82)90001-3

7. Brookes PC, Landman A, Pruden G, Jenkinson DS (1985) Chloroform fumigation and the release of soil nitrogen $A$ rapid direct extraction method to measure microbial biomass nitrogen in soil. Soil Biology Biochemistry 17:837-842. http://doi.org/10.1016/0038-0717(85)90144-0

8. Cao H, Chen R, Wang L, Jiang L, Yang F, Zheng S, Wang G, Lin X (2016) Soil pH, total phosphorus, climate and distance are the major factors influencing microbial activity at a regional spatial scale. Scientific Reports 6:25815. http://doi.org/10.1038/srep25815

9. Chang C, Wu F, Wang Z, Tan B, Cao R, Yang W, Cornelissen JHC (2019) Effects of epixylic vegetation removal on the dynamics of the microbial community composition in decaying logs in an alpine forest. Ecosystems 22:1478-1496. http://doi.org/10.1007/s10021-019-00351-3

10. Chang C, Wang Z, Tan B, Li J, Cao R, Wang Q, Yang W, Weedon JT, Cornelissen JHC (2020) Tissue type and location within forest together regulate decay trajectories of Abies faxoniana logs at early and mid-decay stage. Forest Ecology Management 475:118411.

http://doi.org/10.1016/j.foreco.2020.118411

11. Chen Y, Xu T, Veresoglou SD, Hu H, Hao Z, Hu Y, Liu L, Deng Y, Rillig MC, Chen B (2017) Plant diversity represents the prevalent determinant of soil fungal community structure across temperate grasslands in northern China. Soil Biology Biochemistry 110:12-21. http://doi.org/10.1016/j.soilbio.2017.02.015

12. Coline D, Suzanne D, Sally A, Alison P E, B. and Jeff R, P (2018) Experimentally altered rainfall regimes and host root traits affect grassland arbuscular mycorrhizal fungal communities. Molecular Ecology 27:2152-2163. http://doi.org/10.1111/mec.14536

13. Corrales A, Turner BL, Tedersoo L, Anslan S, Dalling JW (2017) Nitrogen addition alters ectomycorrhizal fungal communities and soil enzyme activities in a tropical montane forest. Fungal Ecology 27:14-23. http://doi.org/10.1016/j.funeco.2017.02.004

14. Edgar RC (2010) Search and clustering orders of magnitude faster than blast. Bioinformatics 26:2460. http://doi.org/10.1093/bioinformatics/btq461

15. Ezawa T, Saito K (2018) How do arbuscular mycorrhizal fungi handle phosphate? New insight into fine-tuning of phosphate metabolism. New Phytologist 220:1116-1121. http://doi.org/10.1111/nph.15187

16. Franklin RB, Mills AL (2009) Importance of spatially structured environmental heterogeneity in controlling microbial community composition at small spatial scales in an agricultural field. Soil Biology Biochemistry 41:1833-1840. http://doi.org/10.1016/j.soilbio.2009.06.003

17. Geisseler D, Scow KM (2014) Long-term effects of mineral fertilizers on soil microorganisms - A review. Soil Biology Biochemistry 75:54-63. http://doi.org/10.1016/j.soilbio.2014.03.023 
18. Grayston SJ, Campbell CD, Bardgett RD, Mawdsley JL, Clegg CD, Ritz K, Griffiths BS, Rodwell JS, Edwards SJ, Davies WJ, Elston DJ, Millard P (2004) Assessing shifts in microbial community structure across a range of grasslands of differing management intensity using CLPP, PLFA and community DNA techniques. Applied Soil Ecology 25:63-84. http://doi.org/10.1016/s09291393(03)00098-2

19. Hodge A, Fitter RH (2010) Substantial nitrogen acquisition by arbuscular mycorrhizal fungi from organic material has implications for $\mathrm{N}$ cycling. Proceedings of the National Academy of Sciences of the United States of America 107:13754-13759. http://doi.org/10.1073/pnas.1005874107

20. Jarosław L, Ewa B, Wojciech P, Małgorzata W (2017) How the deadwood of different tree species in various stages of decomposition affected nutrient dynamics? Journal of Soils Sediments 18:27592769. http://doi.org/10.1007/s11368-017-1858-2

21. Kappes H, Catalano C, Topp W (2007) Coarse woody debris ameliorates chemical and biotic soil parameters of acidified broad-leaved forests. Applied Soil Ecology 36:190-198. http://doi.org/10.1016/j.apsoil.2007.02.003

22. Kuczynski J, Stombaugh J, Walters A, Gonzalez W, Caporaso A, J.G. and Knight R (2011) Using qiime to analyze $16 \mathrm{~s}$ rrna gene sequences from microbial communities. Current Protocols in Bioinformatics 10:10.7. http://doi.org/10.1002/0471250953.bi1007s36

23. Lammel DR, Barth G, Ovaskainen O, Cruz LM, Zanatta JA, Ryo M, de Souza EM, Pedrosa FO (2018) Direct and indirect effects of a $\mathrm{pH}$ gradient bring insights into the mechanisms driving prokaryotic community structures. Microbiome 61:106. http://doi.org/10.1186/s40168-018-0482-8

24. Lassauce A, Paillet $Y$, Jactel H, Bouget C (2011) Deadwood as a surrogate for forest biodiversity: Meta-analysis of correlations between deadwood volume and species richness of saproxylic organisms. Ecological Indicators 11:1027-1039. http://doi.org/10.1016/j.ecolind.2011.02.004

25. Lindahl B, Stenlid J, Olsson S, Finlay R (1999) Translocation of ${ }^{32} \mathrm{P}$ between interacting mycelia of a wood-decomposing fungus and ectomycorrhizal fungi in microcosm systems. New Phytologist 144:183-193. http://doi.org/10.2307/2588287

26. Lindahl BD, Ihrmark K, Boberg J, Trumbore SE, Högberg P, Stenlid J, Finlay RD (2007) Spatial separation of litter decomposition and mycorrhizal nitrogen uptake in a boreal forest. New Phytologist 173:611-620. http://doi.org/10.1111/j.1469-8137.2006.01936.x

27. Lindahl BD, Tunlid A (2015) Ectomycorrhizal fungi - potential organic matter decomposers, yet not saprotrophs. New Phytologist 205:1443-1447. http://doi.org/10.1111/nph.13201

28. Lu R (1999) Soil and Agro-chemical Chemistry Analytical Methods. China Agricultural Science and Technology Press, Beijng

29. Magoč T, Salzberg SL (2011) FLASH: fast length adjustment of short reads to improve genome assemblies. Bioinformatics 27:2957-2963. http://doi.org/10.1093/bioinformatics/btr507

30. Makipaa R, Rajala T, Schigel D, Rinne KT, Pennanen T, Abrego N, Ovaskainen O (2017) Interactions between soil- and dead wood-inhabiting fungal communities during the decay of Norway spruce logs. ISME Journal 11:1964-1974. http://doi.org/10.1038/ismej.2017.57 
31. Minnich C, PerÅjoh D, Poll C, Borken W (2021) Changes in chemical and microbial soil parameters following 8 years of deadwood decay: an experiment with logs of 13 tree species in 30 forests. Ecosystems 24:955-967. http://doi.org/10.1007/s10021-020-00562-z

32. Moorhead DL, Lashermes G, Sinsabaugh RL (2012) A theoretical model of C- and N-acquiring exoenzyme activities, which balances microbial demands during decomposition. Soil Biology Biochemistry 53:133-141. http://doi.org/10.1016/j.soilbio.2012.05.011

33. Morrison EW, Frey SD, Sadowsky JJ, van Diepen LTA, Thomas WK, Pringle A (2016) Chronic nitrogen additions fundamentally restructure the soil fungal community in a temperate forest. Fungal Ecology 23:48-57. http://doi.org/10.1016/j.funeco.2016.05.011

34. Nguyen NH, Song Z, Bates ST, Branco S, Tedersoo L, Menke J, Schilling JS, Kennedy PG (2016) FUNGuild: An open annotation tool for parsing fungal community datasets by ecological guild. Fungal Ecology 20:241-248. http://doi.org/10.1016/j.funeco.2015.06.006

35. Oksanen J, Blanchet FG, Kindt R, Legendre P, Minchin PR, O'Hara RB, Simpson GL, Solymos P, Stevens MHH, Wagner HH (2013) Vegan: community ecology package. R package version. 2.0-10. http://CRAN.R-project.org/package=vegan

36. Pfennigwerth AA, Van Nuland ME, Bailey JK, Schweitzer JA (2018) Plant-soil feedbacks mediate shrub expansion in declining forests, but only in the right light. Journal of Ecology 106:179-194. http://doi.org/10.1111/1365-2745.12833

37. Pongsilp N, Nimnoi P (2020) Inoculation of Ensifer fredii strain LP2/20 immobilized in agar results in growth promotion and alteration of bacterial community structure of Chinese kale planted soil. Scientific Reports 10:15857. http://doi.org/10.1038/s41598-020-72986-5

38. Purahong W, Wubet T, Lentendu G, Schloter M, Pecyna MJ, Kapturska D, Hofrichter M, Krüger D, Buscot $F$ (2016) Life in leaf litter: novel insights into community dynamics of bacteria and fungi during litter decomposition. Molecular Ecology 25:4059-4074. http://doi.org/10.1111/mec.13739

39. R Development Core Team (2015) R: A Language and Environment for Statistical Computing. $R$ Foundation for Statistical Computing, Vienna. http://www.r-project.org/

40. Rajala T, Peltoniemi M, Hantula J, Mäkipää R, Pennanen T (2011) RNA reveals a succession of active fungi during the decay of Norway spruce logs. Fungal Ecology 4:437-448. http://doi.org/10.1016/j.funeco.2011.05.005

41. Semchenko M, Leff JW, Lozano YM, Saar S, Davison J, Wilkinson A, Jackson BG, Pritchard WJ, De Long JR, Oakley S, Mason KE, Ostle NJ, Baggs EM, Johnson D, Fierer N, Bardgett RD (2018) Fungal diversity regulates plant-soil feedbacks in temperate grassland. Science Advances 4:eaau4578. http://doi.org/10.1126/sciadv.aau4578

42. Tedersoo L, Bahram M, Põlme S, Kõljalg U, Yorou NS, Wijesundera R, Ruiz LV, Vasco-Palacios AM, Thu PQ, Suija A, Smith ME, Sharp C, Saluveer E, Saitta A, Rosas M, Riit T, Ratkowsky D, Pritsch K, Põldmaa K, Piepenbring M, Phosri C, Peterson M, Parts K, Pärtel K, Otsing E, Nouhra E, Njouonkou AL, Nilsson RH, Morgado LN, Mayor J, May TW, Majuakim L, Lodge D, Lee SS, Larsson K-H, Kohout P, Hosaka K, Hiiesalu I, Henkel TW, Harend H, Guo LD, Greslebin A, Grelet G, Geml J, Gates G, Dunstan 
W, Dunk C, Drenkhan R, Dearnaley J, Kesel AD, Dang T, Chen X, Buegger F, Brearley FQ, Bonito G, Anslan S, Abell S, Abarenkov K (2014) Fungal biogeography. Global diversity and geography of soil fungi. Science 346:6213. http://doi.org/10.1126/science.1256688

43. Vance ED, Brooke PC, Jenkinson DS (1987) An extraction method for measuring soil microbial biomass C. Soil Biology Biochemistry 19:703-707. http://doi.org/10.1016/0038-0717(87)90052-6

44. Wang Q, Yang W, Li H, Wang Z, Chang C, Cao R, Tan B (2021) Changes in carbon, nitrogen and phosphorus stoichiometry in decaying logs with gap positions in a subalpine forest. Journal of Plant Ecology 14:692-701. http://doi.org/10.1093/jpe/rtab023

45. Wojciech P, Ewa B, Jarosław L, Martin L (2019) A comparison of C:N:P stoichiometry in soil and deadwood at an advanced decomposition stage. Catena 179:1-5. http://doi.org/10.1016/j.catena.2019.03.025

46. Xiao S, Wu F, Yang W, Chang C, Li J, Wang B (2014) Understory biomass and its characteristics as affected by forest gap in the alpine forest ecosystem in West Sichuan. Ecology Environmental Sciences 23:1515-1519. http://doi.org/10.3969/j.issn.1674-5906.2014.09.018

47. Xiao S, Wu F, Yang W, Chang C, Li J, Wang B, Cao Y (2016) Woody debris storage and its distribution in a dark coniferious forest in the alpine-gorge area. Acta Ecologica Sinica 36:1352-1359. http://doi.org/10.5846/stxb201407171458

48. Yang W, Wu F (2021) The ecosystem processes and adaptive management of the subalpine coniferous forests in the upper reaches of Yangtze river. Science Press, Beijing

49. Zalamea M, González G, Lodge D (2016) Physical, chemical, and biological properties of soil under decaying wood in a tropical wet forest in Puerto Rico. Forests 7:168-186. http://doi.org/10.3390/f7080168

50. Zhang X, Chen X, Liu M, Xu Z, Wei H (2020) Coupled changes in soil organic carbon fractions and microbial community composition in urban and suburban forests. Scientific Reports 10:15933. http://doi.org/10.1038/s41598-020-73119-8

\section{Figures}



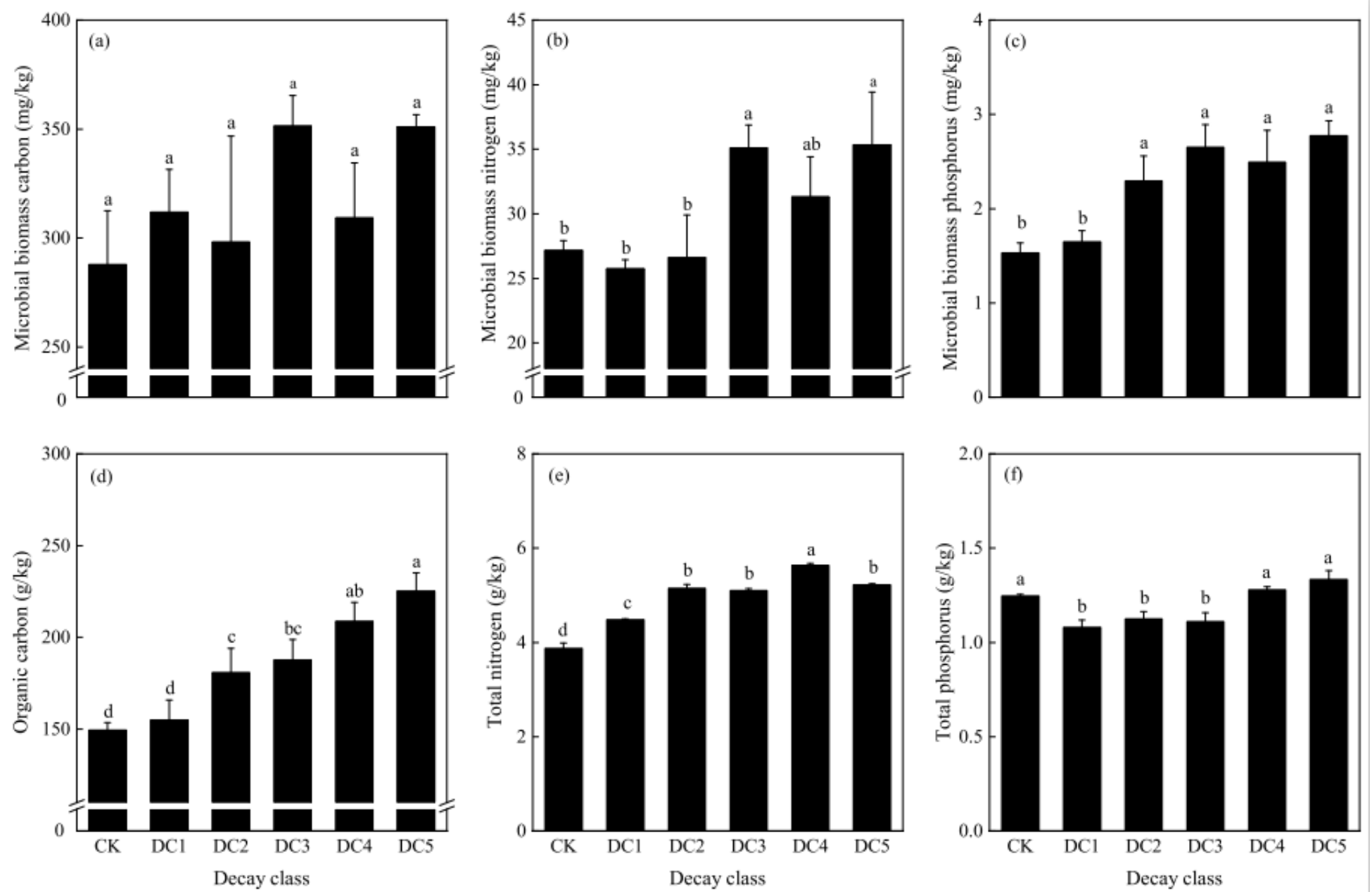

Figure 1

Concentrations of microbial biomass carbon (a), microbial biomass nitrogen (b), microbial biomass phosphorus (c), organic carbon (d), total nitrogen (e) and total phosphorus (f) in the soil under decaying logs in the decay classes (mean $\pm S D, n=5$ ). CK, control; DC1-DC5, decay classes I-V. Different letters indicate significant differences $(P<0.05)$ among the decay classes 

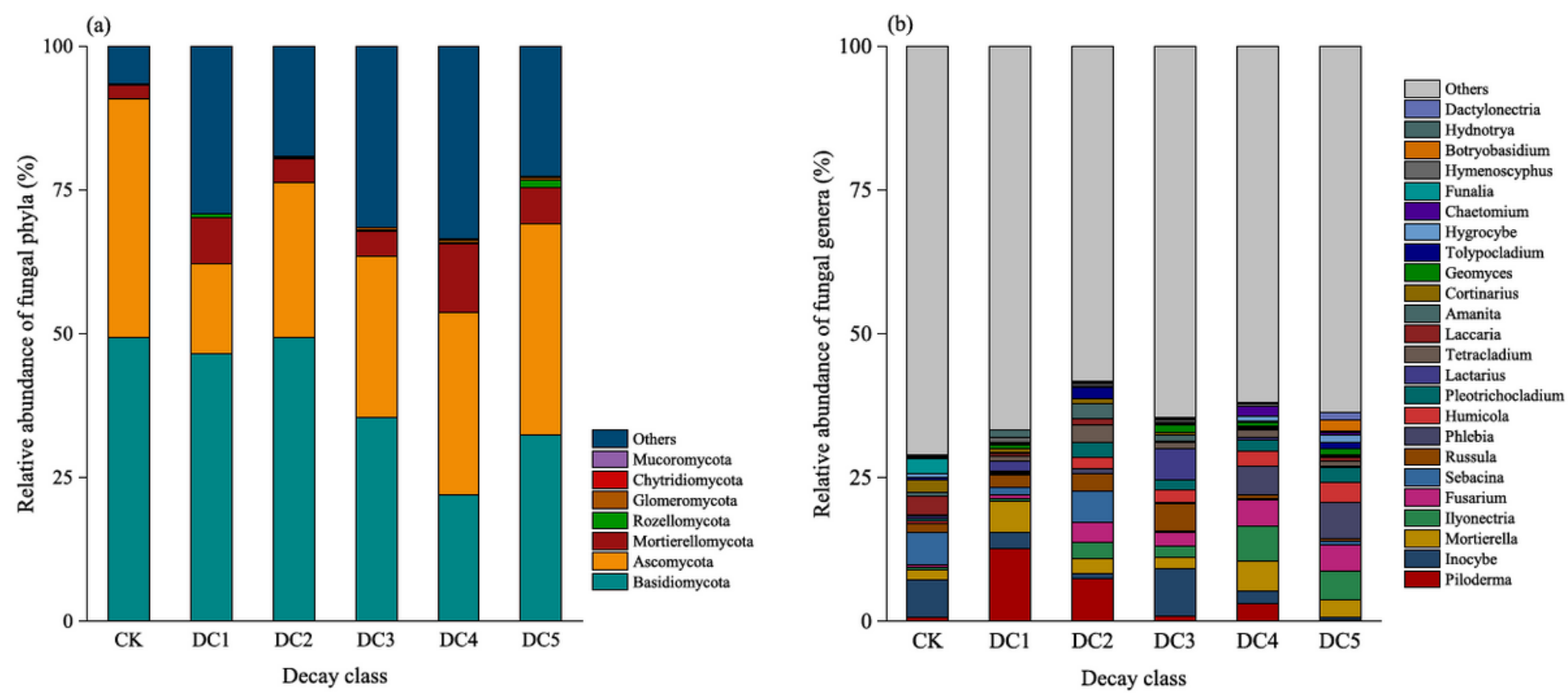

Figure 2

Relative abundances ( $>1 \%$ ) of fungi at the phylum (a) and genus (b) levels in the control (CK) and the decay classes (ranked by the sum of means). DC1-DC5, decay classes I-V. Data are the means of five samples for each group

(a)

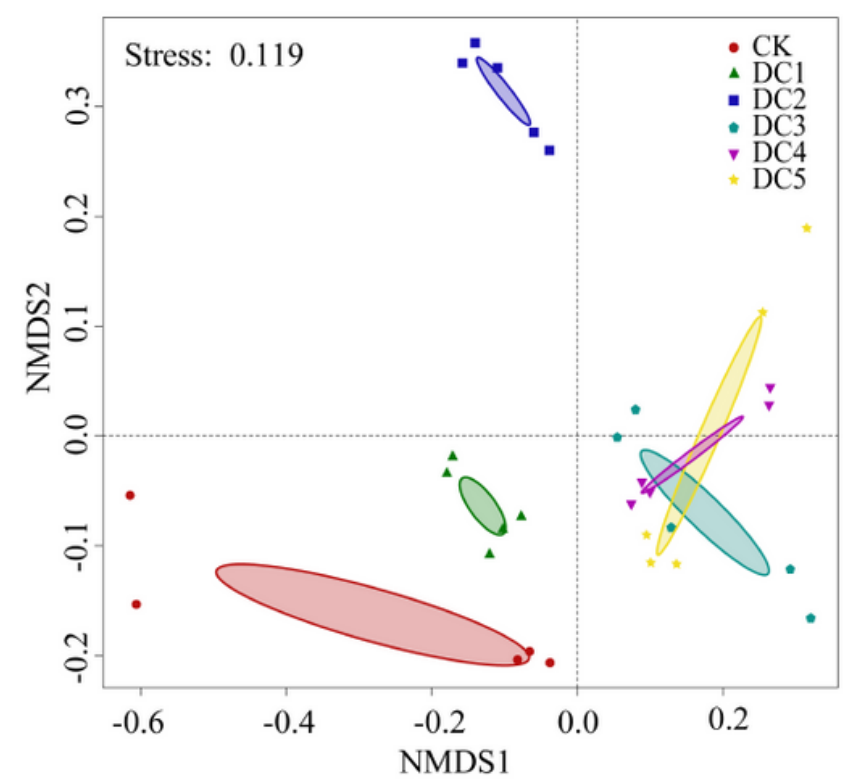

(b)

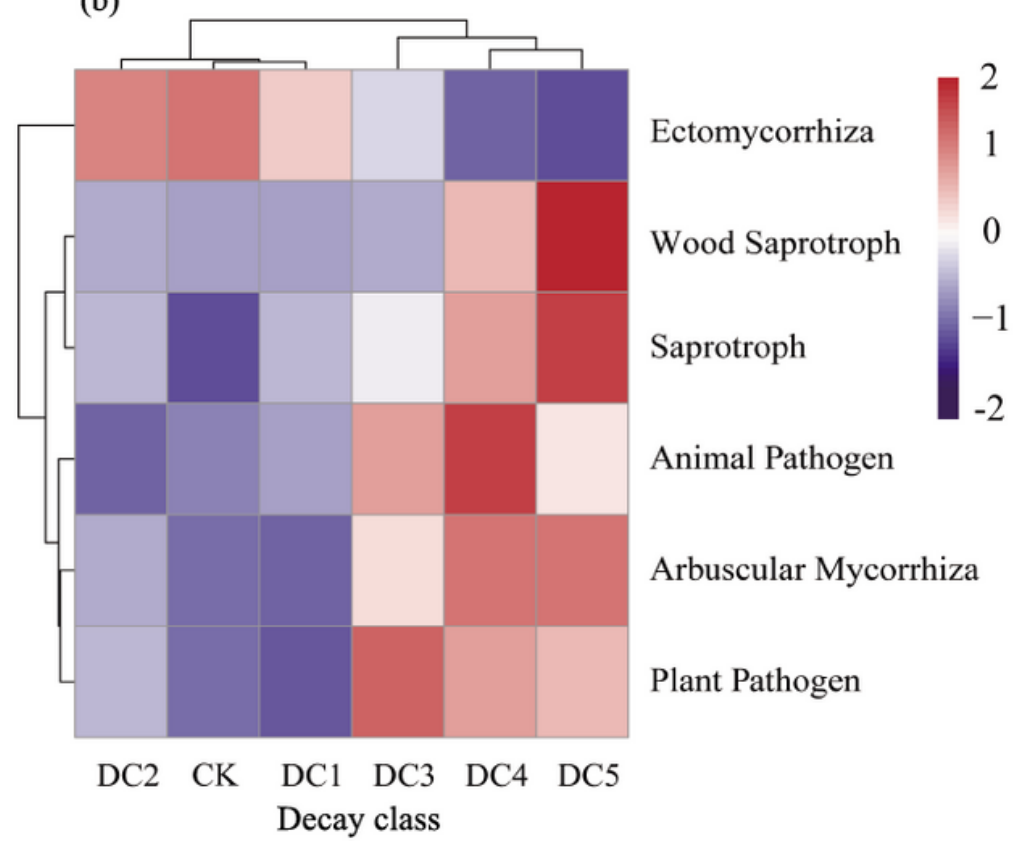

\section{Figure 3}

The response of soil fungal community to decaying logs. Nonmetric multidimensional scaling (NMDS) analysis of the composition of soil fungal communities (a) based on Bray-Curtis distances. Heatmap of 
soil fungal functional groups (b) from different decay classes of logs. CK, control; DC1-DC5, decay classes I-V
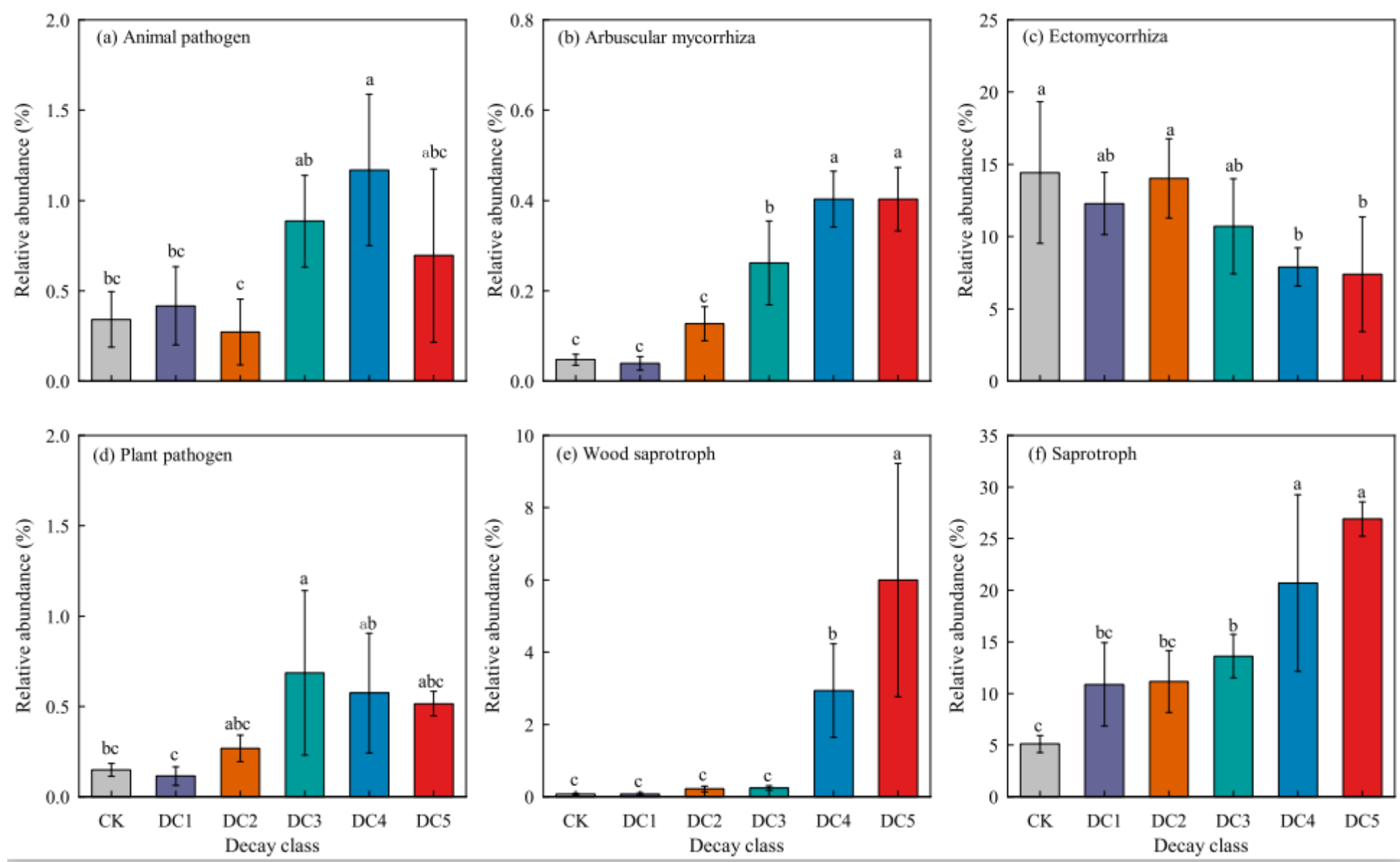

Figure 4

Fungal functional groups (guild) under different treatments (mean $\pm S D, n=5$ ). CK: blank control group. DC1-DC5: decay classes I-V. Different lowercase letters indicate significant differences $(P<0.05)$ among decay classes 
(a)

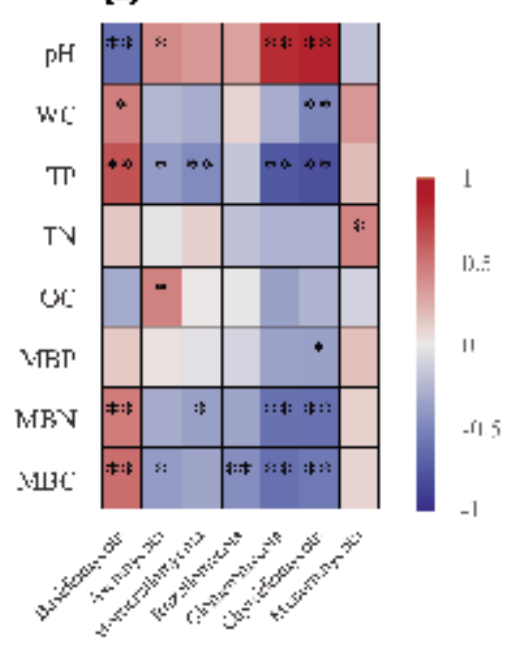

(b)

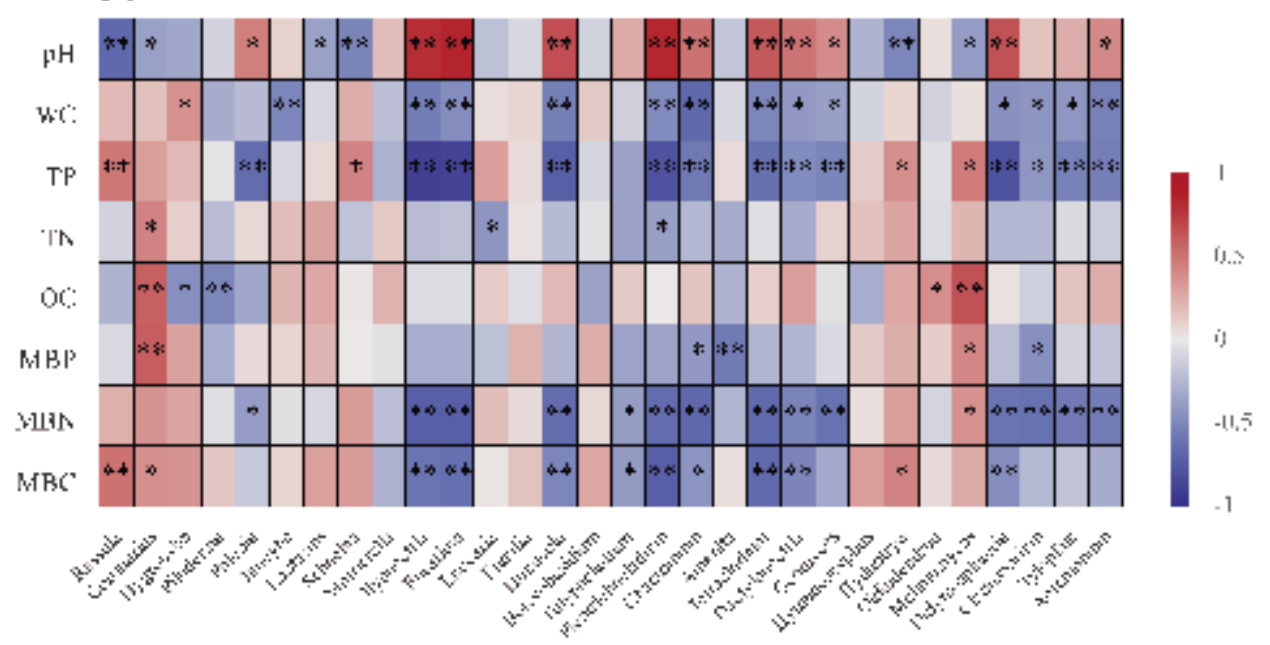

\section{Figure 5}

Correlation heatmap of soil biochemical properties and the relative abundances of soil fungi at phylum (a) and genus (b) level. MBC: microbial biomass carbon, MBN: microbial biomass nitrigen, MBP: microbial biomass phosphorus, OC: organic carbon, TN: total nitrogen, TP: total phosphorus, WC: water content. * $P<0.05, * \star P<0.01$

\section{Supplementary Files}

This is a list of supplementary files associated with this preprint. Click to download.

- Supplementaryfiles.pdf 